\title{
Perspektief vir genestelde klimaatmodellering oor suidelike Afrika
}

\author{
F.A. Engelbrecht en C.J. de W. Rautenbach \\ Departement Aardwetenskappe, Fakulteit Natuur- en Landbouwetenskappe, Universiteit van Pretoria, Pretoria, 0002
}

Ontvang 2I Januarie 2000; aanvaar II Maart 2000

\section{UITTREKSEL}

Die klimaat van suidelike Afrika word wesenlik bë̈nvloed deur mesoskaal-sirkulasiepatrone wat nie na wense gesimuleer word deur. globale atmosferiese algemene sirkulasiemodelle (AASM'e) nie. Die tegniek van genestelde klimaatmodellering (GKM), maak gebruik van hoëroosterresolusie-beperkte-areamodelle (BAM'e) om klimaatsimulasies van die mesoskaal te verkry uit oorwegend sinoptiese skaal-AASM-resultate. Hier word die modifiserende invloed van mesokaalforsering en sirkulasiepatrone op die klimaat van suidelike Afrika uitgelig. Die toepaslikheid van sommige teoretiese aspekte van GKM-tegnieke oor suidelike Afrika word bespreek, en GKMeksperimente wat reeds oor die streek uitgevoer is, word onder die loep geneem. 'n Benadering wat gevolg kan word om die klimaat van suidelike Afrika op mesoskaal te modelleer; word voorgestel. .

\begin{abstract}
Perspective for nested climate modelling over southern Africa

The climate of southern Afirica is fundamentally affected by mesoscale circulation patterns that are not adequately simulated by global atmospheric general circulation models (AGCMS). The technique of nested climate modelling (NCM) utilises high-resolution limited area models (LAMs) to obtain climate simulations of the mesoscale from essentially synoptical scale AGCM results. This study outlines the modifying influence of mesoscale forcing and circulation patterns on the southern African climate. The applicability of certain theoretical aspects of NCM techniques for the southern African subregion is discussed, and NCM experiments already performed over the region are highlighted. An approach that may be followed to model the climate of southern Africa on the mesoscale is proposed.
\end{abstract}

\section{INLEIDING}

In Suid- $\Lambda$ frika is daar 'n toenemende besef onder die wetenskaplike gemeenskap, beleidmakers en dic publick dat tockomstige globale klimaatsverandering ingrypende gevolge vir suidelike Afrika kan hê. Globale klimaatsverandering word onder meer voorsien weens die wêreldwye toename in konsentrasies van sommige kweekhuisgasse in die atmosfeer, ' asook die vernietiging van reënwoude. ${ }^{2.3}$ Ook oor suidelike Afrika kan die moontlike verskuiwing van klimaatsones en meer gereelde vloede, droogtes en hittegolwe lei tot maatskaplike, ekonomiese en politieke ontwrigting. ${ }^{4}$ Modellering van die toekomstige klimaat op streekskaal is dus van die allergrootste belang.

Om klimaat op streekskaal te modelleer, behels die simulasie van klimaat-forserende meganismes op twee verskillende ruimtelike skale: Die grootskaal, wat strek van 'n paar honderd $\mathrm{km}$ tot globaal en die mesoskaal, gedefinieer as 'n paar kilometer tot ongeveer $100 \mathrm{~km} .{ }^{5}$ Grootskaalse forserings, soos dié veroorsaak deur die roterende aarde en die volopheid van atmosferiese gasse, beheer globale sirkulasie. Die globale sirkulasie bepaal weer die opeenvolging van weergebeurtenisse wat die klimaat van 'n sekere streek tipeer. Mesoskaalforserings soos geïnduseer deur komplekse topografie en oppervlakeienskappe, modifiseer die struktuur van weergebeurtenisse en lei tot mesoskaalsirkulasies. Binne die grootskaalse sirkulasiesisteme dra hierdie sirkulasies daartoe by om die streeksverspreiding van klimaatsveranderlikes te bepaal. ${ }^{5}$

Globale atmosferiese algemene sirkulasiemodelle (AASM'e), wat driedimensionele voorstellings van die atmosfeer bied, is tans die vernaamste metode om die klimaat te simuleer. ${ }^{5}$ Alhoewel AASM'e die hoofeienskappe van die gemiddelde atmosferiese sirkulasie, asook die interjaarlikse veranderlikheid in die atmosferiese sirkulasie oor suidelike Afrika relatief goed weergee, ${ }^{6,7,8}$ is simulasies van plaaslike klimate onbevredigend. Hierdie resultaat kan grotendeels toegeskryf word aan die relatief lae horison- tale roostcrresolusic van dic globale AASM'e wat vir die klimaatsimulasies gebruik is. Vir hedendaagse klimatologiese toestande, met vaste grootskaalforsering, is die CSIRO9 MARK II AASM van Australië byvoorbecld geloop met spektrale roosterresolusies van R21 $\left(3.2^{\circ}\right.$ by $\left.5.6^{\circ}\right)$ en $\mathrm{T} 63\left(1.87^{\circ}\right.$ by $\left.1.87^{\circ}\right)$. Die berekeningsvereistes wat globale numeriese klimaatmodellering aan rekenaarkapasiteit stel, is sekerlik die hoofrede waarom globale AASMklimaatsimulasies nie op mesoskaal-roosterresolusies uitgevoer kan word nie. Die aard van klimaatsimulasies vereis dat die AASM'e vir lang integrasietydperke (wat kan wissel van maande tot jare) geloop word, sodat kragtiger rekenaars vereis word namate die roosterresolusie van modelle fyner word. ${ }^{5,9}$ Gekoppelde oseaan-see-ys-atmosfeer-modelle word geloop met selfs growwer resolusies as hedendaagse AASM'e, en sluit slegs hoogs vereenvoudige weergawes van hidrosferiese en krysosferiese komponente in. Hierdie modelle moet vir lang simulasieperiodes geloop word voordat die verskillende komponente 'n toestand van ewewig bereik. ${ }^{5}$ Geen gekoppelde klimaatmodelsimulasie is tot op hede in Suid-Afrika uitgevoer nie weens die gebrek aan die beskikbaarheid van superrekenaars om die uiters tydrowende numeriese integrasies te voltooi.

Met tipiese AASM-roosterresolusiesimulasies kan die effek van sinoptieseskaal-forserings op die algemene atmosferiese sirkulasie wel vasgevang word, maar belangrike kleiner skaal atmosferiese verskynsels, soos tropiese siklone, kan nie na wense as subroosterskaal-prosesse geparameteriseer word met hierdie resolusie nie. Ook die impak van lokale forserings wat voortspruit uit byvoorbeeld komplekse topografie en aardoppervlakeienskappe, en wat die veranderlikheid van die klimaat oor groot dele van suidelike Afrika sterk beïnvloed, gaan verlore. Die onvermoë om mesoskaal atmosferiese veranderlikheid in globale AASM-simulasies vas te vang, affekteer in 'n mate ook simulasies van die atmosfeer deur AASM'e op groter ruimtelike skale.,

Klimaatsveranderingimpak-analises wat oor suidelike Afrika 
uitgevoer is, het hoofsaaklik gebruik gemaak van klimaatsneigings soos gesimuleer deur lacresolusic- $\Lambda \wedge S M^{\prime}{ }^{\prime}{ }^{10}{ }^{10} \mathrm{Dic}$ gebrek aan fyner besonderhede in hicrdic analises het 'n nadelige uitwerking op dic beraande impak van klimaatsverandering in streekverband (oor suidelike $A$ frika). Die probleem om meer detail in dic klimaatsimulasic oor die streck te verkry, uit lacresolusic- $\triangle \wedge \mathrm{SM}$-resultate, moet dus aandag kry.

Die tegnick van genestelde klimaatmodellering (GKM), waar gebruik gemaak word van hoëroosterresolusie-beperkte-areamodelle ( $\mathrm{B} \wedge \mathrm{M}$ 'e), is ecn moontlike benadering wat gevolg kan word om laasgenoemde problecm op te los. Die tegnick kom daarop neer dat ' $n$ hočroosterresolusic- $B \wedge M$ van randwaardes voorsien word deur' 'n globale $\triangle A S M$, terwyl beide modelle vir verlengde periodes geïntegreer word ten einde klimaatsimulasies te verkry.

In hierdie artikel word dic modifiserende invloed van mesoskaalforsering en sirkulasicpatrone op dic klimaat van suidelike Afrika kortliks bespreck. Dit word gevolg deur 'n bekrywing van dic GKM-tegnick waar gepoog word om mesoskaaleffekto in modelsimulasies vas te vang. Laastens word GKM-eksperimente, wat recds oor die subkontinent uitgevoer is, bespreck. Die doclwit van hierdic artikel is dus om 'n aanduiding te gee van die toepaslikheid van sommige teoretiese aspekte van GKMtegnicke op suidelike $A$ frika. 'n Voorgestelde benadering om dic klimaat van die subkontinent op mesoskaal te modellecr, word aangebied, met die oogmerk om verdere bespreking onder die modelleringsgemeenskap aan te moedig.

MESOSKAALFORSERING OOR SUIDELIKE AFRIKA Mesoskaal atmosferiese forsering word hoofsaaklik veroorsaak deur die komplekse verspreiding van oppervlakeienskappe soos orografie, kuslyne, binnelandse watermassas en plantegroei. Hierdie eienskappe varieer op 'n ruimtelike skaal van sowat 10 tot $100 \mathrm{~km}^{5}$

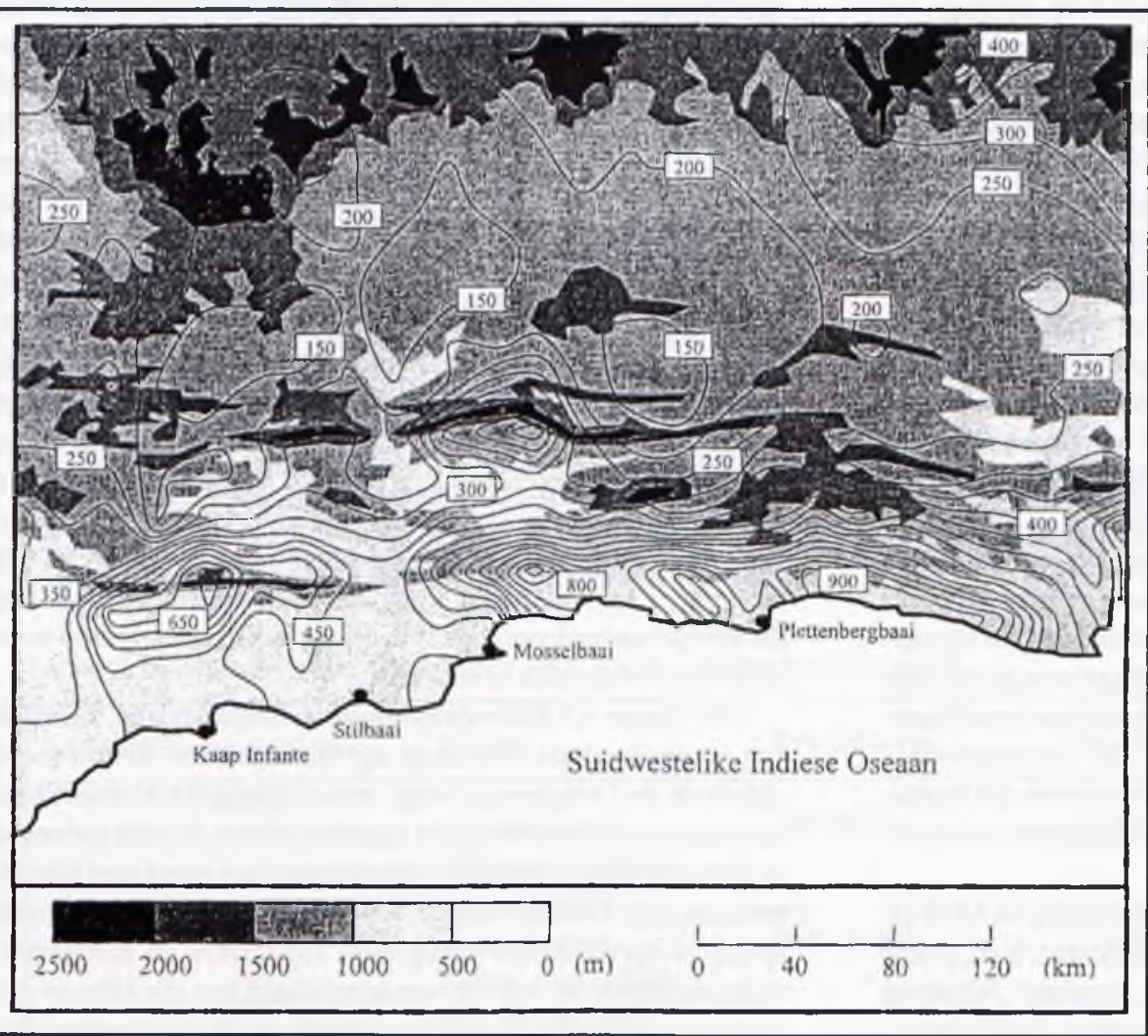

Figuur I: Orografie (skadu met $500 \mathrm{~m}$ intervalle) oor die Klein-Karoo en Suidkus (20" tot $25^{\prime \prime}$ Oos en $32^{\prime \prime}$ tot $35^{\circ}$ Suid) en isohiëte van die gemiddelde jaarlikse totale reënval gemeet in millimeter $(\mathrm{mm})$. Let op die toename in plaaslike reënvaltotale teen die hellings van en oor hoër orografie.
Reenval word onder meer sterk beînvloed deur die orografie (byvoorbeeld kondensasic vanweë orografiese opligting). Figuur 1 illustreer die orografie en waargenome gemiddelde jaarlikse reènval oor die Klein-Karoo en die Suidkus $\left(20^{\circ}\right.$ tot $25^{\circ}$ Oos en $32^{\circ}$ tot $35^{\circ}$ Suid). Betreklik droë toestande heers oor die KleinKaroo wat in die reënskadu van die Lange- en Outeniekwaberge lê, terwyl hoêr plaaslike reënvaltotale voorkom teen die hellings van, of oor gebiede met groter hoogtes bo seespiec̈l. Figuur 1 beklemtoon die verskynsel dat groot veranderings in reënvaltotale oor redelike klein afstande kan voorkom.

Mesoskaalforsering kan ook van termiese oorsprong wees, soos veroorsaak deur verskille in die verhitting van land- en oscaanmassas. Op hierdie wyse ontstaan land-secbriessirkulasies wat die plaaslike klimaat van kusgebiede wesenlik kan beinvloed. $\Lambda$ an die noordweskus van Madagaskar vorm landsecbriessirkulasie die dominerende wind. " Die sterkste secbries in suidelike $\Lambda$ frika kom aan die Namibiese kus voor, wat gekenmerk word deur sterk temperatuurgradiënte tussen dic oscaan en land. Hierdie bries, vanaf die suid-suidweste, waai veral gedurende middae wat volg op kalm en oortrokke oggende." Gedurende die somer word vogtige, relatiewe koel lug byna daagliks oor die Natalse kus geadvekteer deur 'n seebries, soms sover as $60 \mathrm{~km}$ die binneland in. "2 Secbriessirkulasies word meestal beïnvloed deur gradientwinde van groter skaal druksisteme oor die see (figuur 2), en die gekombineerde effek van hierdie winde bepaal die rigting van indringing van die seebries oor die binneland van Natal.'2 Die sterk hellende orografic (Drakensberge) veroorsaak voorts dic ontstaan van 'n bergvlaktewind gedurende die nag en valleiwinde gedurende die dag. ${ }^{13.14}$ Wanneer die gradientwinde, hellingsirkulasies en landsecbries-sirkulasies in interaksie trec, kan dit lei tot komplekse dinamiese vlocipatrone in dic mesoskaal.

Groot binnclandse watermassas, soos byvoorbecld dic Victorianeer, het 'n noemenswaardige effek op die plaaslike atmosferiese sirkulasic en beïnvloed ook dic klimaat van dic omliggende gebicde. Dic meer is geleë op die ewenaar in 'n vallei tussen twee bergreckse. Dic unicke orografiese eienskappe skep intense mesoskaalsirkulasiepatrone met sterk daaglikse siklusse in temperatuur en reenval. Daar word vermoed dat donderstormfrekwensies oor die Victoriameer van dic hoogste in die wêreld is. ${ }^{\text {Is }}$

Interaksies tussen meso- en sinoptieseskaal-sirkulasiepatrone beïnvloed ook dic klimaat oor sekere dele van suidelike $A$ frika. So byvoorbecld is die voorkoms van swaar, lokale donderstorms oor dic platorand van Mpumalanga en dic Noordelike Provinsic die produk van minstens dric skale van beweging in die atmosfeer. ${ }^{16}$ Op sinoptiese skaal word ' $n$ weswaartsbewegende trog op of bo dic $850 \mathrm{hPa}$-drukvlak geproduseer, wat westelike tot noordwestelike vloei oor dic noordoostelike platorand versterk. Op dic mesoskaal vorm 'n dekselinversic oor dic platorand deur of adveksic, of subsidensic, van Hoëveld-lug (figuur 3). Plaaslike invlocde versterk dic lugvloci oor dic platorand (sowel die $850 \mathrm{hPa}$ westelike vloci as die oppervlak oostelike vloci van 
vogtige Laeveld-lug). Dic oppervlak oostelike vloci wat die 850 hPa westelike vloei (afkomstig van die Hoeveld) ondersny, is waarskynlik van die sinoptieseskaal- en mesoskaalvloci (platorandverhitting) afhanklik. ${ }^{16}$ Indien dic indringing van vogtige Laeveld-lug na die platorand vroegtydig, en ver genocg na wes plaasvind, kom swaar konvekticwe storms voor oor gebiede waar geen dempende inversie deur subsidensic of adveksic gevorm is nic.

Hierdie voorbee/de illustreer onteenseglik die behoefte alan hoêroosterresolusie (mesoskaal)-informasic. Alhocwel globale $\triangle \wedge \mathrm{SM}$ 'e met growwe roosterresolusies in stat is om inligting te verskaf rakende grootskaalse sirkulasiepatrone oor suidelike Afrika, is hierdic modelie nic geskik om mesoskaalpatrone, soos bespreck in hierdic afdeling, suksesvol te simuleer nic.

\section{GENESTELDE KLIMAATMODELLERING}

$\Lambda \mathrm{s}$ 'n alternaticf vir growweroosterresolusic- $\mathrm{A} \mathrm{SM}$-klimaatsimulasies is dit moontlik om gedetaillecrde klimatsimulasies vir beperkte areas van die aarde te verkry deur middel van 'n tegnick wat bekend staan as genestelde klimaatmodellering (GKM). GKM behels die nes van 'n hoëroosterresolusic-BAM binne die ruimtelike roosterveld van 'n $\triangle \wedge$ SM. Dic $\triangle \wedge S M$ verskaf rand-en beginwaardes an die $B \wedge M$, wat met 'n hoe roosterresolusic (van 10-100 km), in statat is om sommige mesoskaaleienskappe van dic atmosfecr te simulecr. Dit kan lej tot 'n meer realistiese uitbeelding van 'n spesifieke streck se

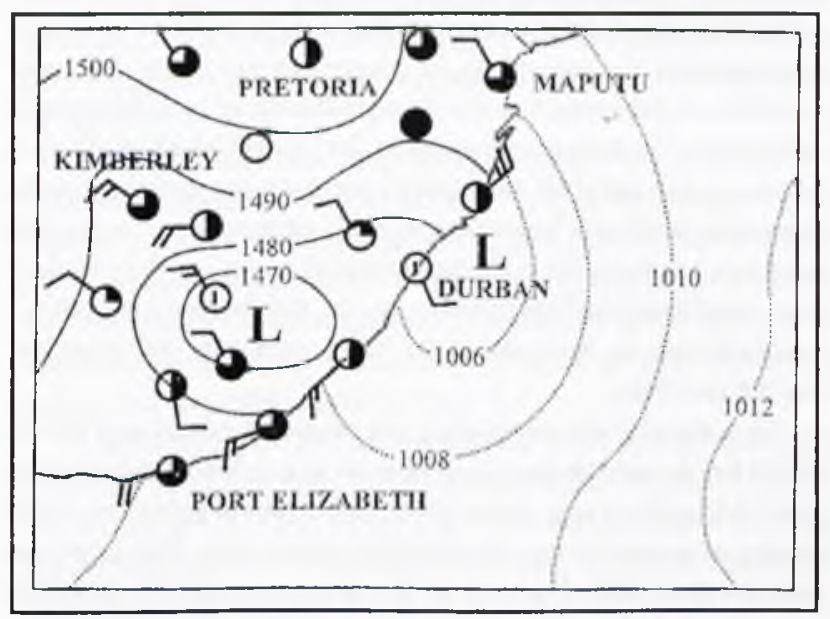

Figuur 2: Gradiëntwinde soos geïduseer deur 'n kuslaag oor. die Indiese Osearn kan die indringing van die seebries oor die Natalse bimneland verdiep. Die figumr toon geopotensiäle hoogtes (gpm) van die 850 hPa-drukvlak oor die land (soliede kontoere) en isobare (stippellyne) gereduseer tot gemiddelde seevlakdruk (hPa) oor die osean, soos op 14 Jamuarie 1968 oin 14:00.

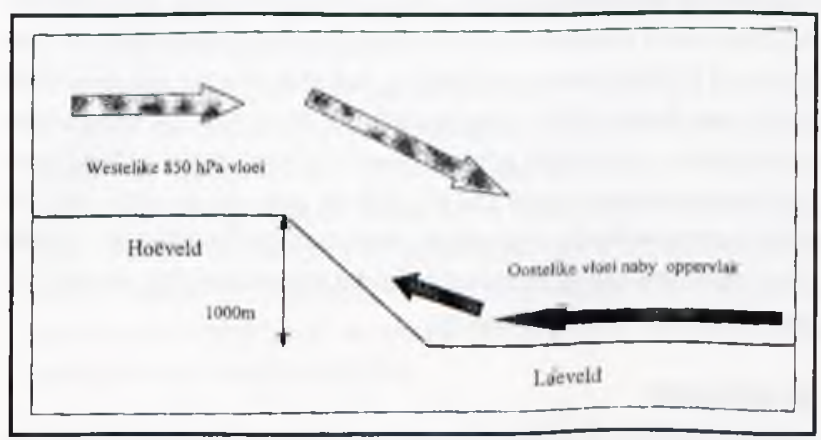

Figuar 3: Interaksie tussen sinoptiese en mesoskatvloei relatief tot die noordoostelike platorand van Suid-Afirika. Hierdie vloei kan lei tot die ontwikkelling van swar donderstorms (gebaseer op Garstang en andere $\left.e^{6}\right)$. klimaat. Die nestelmetode kan toegepas word deur 'n nieinteraktiewe (een-rigting) of interaktiewe (twee-rigting) wyse. Eersgenoemde word voorgestel in figuur 4 wat daarop dui dat inligting afkomstig van die lacroosterresolusie- $\triangle \wedge$ SM gebruik word om die hoēroosterresolusic-BAM aan te dryf. Let daarop dat inligting van dic $B \wedge M$ nie teruggevoer word na die lacroosterresolusie-gebied van die $\triangle \triangle S M$ nie. Die interaktiewe metode (inligting vloei interaktief in beide rigtings tussen die hoci- en lacroosterresolusicmodelle) is mocilik haalbaar wanneer die globale $\triangle \triangle S M$ spektrale velde analiseer, terwyl die genestelde model slegs roosterveldanalises uitvoer." Indien die globale model 'n klimaatmodel is, kan willekeurige terugvoer van inligting vanaf die $B \wedge \mathrm{M}$ nadelig dien as ' $n$ kunsmatige bron of put van energie, en sodoende die behoudseienskappe van die $\wedge \wedge \mathrm{SM}$ omverwerp."

Tydens die ontwikkeling van ' $n$ genestelde klimaat- $B \wedge M$ is dit noodsaaklik om die area van belang sowel as dic dimensies van die horisontale roosterresolusic te definiecr. Die roosterresolusic moet fyn genoeg wees om dic relevante mesoskaalsirkulasiepatrone vas te vang, terwyl dic area van belang groot genoeg moet wees om te verhoed dat die lacroosterresolusierandwaardes dic oplossing oor die totale area domineer. Die BAM-gesimuleerde mesoskaal-sirkulasiestelsels moet dus ten volle binne die gekose gebied kan ontwikkel. ${ }^{17,18}$ Dit is voorts waarskynlik dat die interne $B \wedge M$-fisika se belangrikheid toeneem namate die BAM-gebied vergroot. Dit vergroot die moontlikheid dat die B $\triangle \mathrm{M}$ moontlik grootskaalse foute, soos gesimuleer deur die globale $\triangle \triangle S M$, kan modifiseer. ${ }^{5} \wedge$ an die ander kant is daar gevind dat die beperkte gebied vir die $B \wedge \mathrm{M}$ klein genoeg moet wees om te verseker dat die interne sinoptieseskaal-sirkulasiepatrone nic afwyk van dic van dic aandrywende $\triangle \triangle S M$ nic. ${ }^{13.18}$ Die aantal roosterpunte vir die BAM moet ook nie so groot wees dat die modelsimulasies berekeningsgewys te duur word nie. 'n Middeweg moet dus gevind word tussen die roosterresolusie wat benodig word en dic beskikbare rekenaarkapasiteit.

Die toepassing van een-rigting-B $\triangle M$ 'e op mesoskaalklimaatmodellering berus op die aanname dat die ontwikkeling van sisteme binne die genestelde modelgebied beperk word deur forsering van randwaardes vanaf dic $\Lambda \Lambda S M$. Dic invoer van

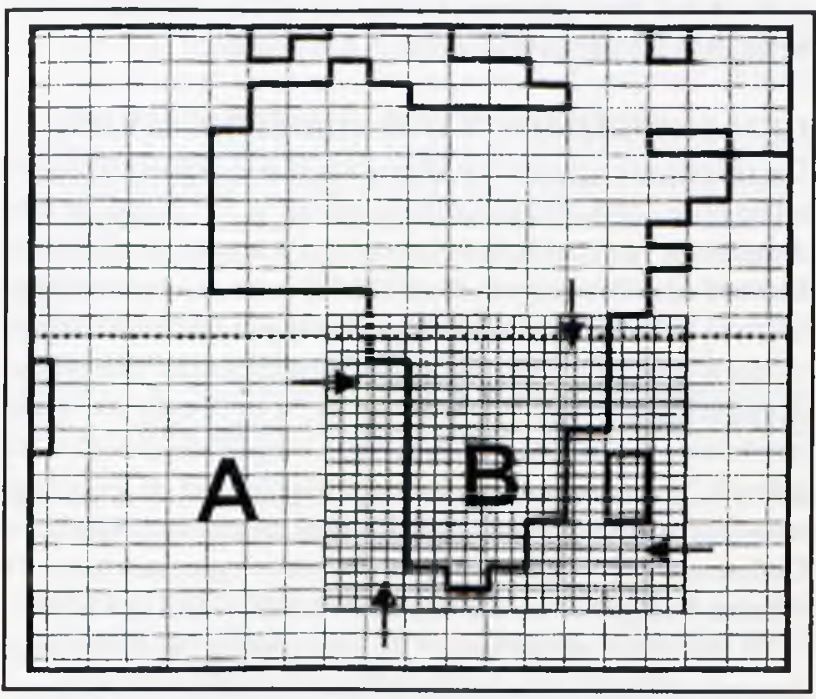

Figuar 4: Die roosterblokresolusie van 'n tipiese globale atmosferiese model oor Afrika. 'n Fyner resolusiebeperkte areamodel (B) word binne die globale modelrooster (A) genestel. Inligting word tocgelas om vanaf die globale model oor die wande van die fyner resolusiemodel te vloei gedurende die modelintegrasies, man vloei in die teenoorgestelde rigting word nie toegelant nie. 
randwaardes dien ten doel om vloei-onversoenbaarhede te verwyder, veral in gebiede waar weersisteme gereeld deur die gebied beweeg." In die trope, waar weersisteme normaalweg stadiger beweeg as in middelbreedtegebiede, is dit moontlik dat semistasionêre sisteme binne dic genestelde gebied kan ontwikkel met 'n lewensiklus onafhanklik van die AASM-forsering. ${ }^{20}$ Die eenrigting-nestingmetode het dus teoretiese beperkings in die trope, en die GKM-tegniek sal moontlik beter vaar in die middelbreedtes. Dic vraag ontstaan of hierdic "stasionêre probleem" dic GKM-tegnick ontoepasbaar maak vir groot dele van suidelike $\wedge$ frika wat gedomineer word deur tropiese sirkulasiestelsels. 'n Goeic aanduiding dat die GKM-tegnick wel toepasbaar is, word verskaf deur suksesvolle GKM-simulasies van dic Australiese klimaat, wat oor uitgebreide gebiede noord en suid van dic ewenaar uitgevocr is. ${ }^{20}$

Dit is ook noodsaaklik om Madagaskar in 'n beperkte gebied in te sluit wanneer klimaatsimulasies oor suidelike Afrika uitgevoer word. Detail van dic Madagaskar-orografie word nic voldoende geïnkorporeer in die gladgemaakte velde van AASM'e nic. Dit kan dic AASM-simulasies van byvoorbecld Mosambiekse sirkulasiepatrone moontlik nadelig raak. ${ }^{21}$

'n Gocic aanbeveling is ook dat dic rande van 'n $B \wedge M$ ver van dic subkontinent se kuslyne gekies word, sodat interpolasie vanaf die AASM na die BAM makliker uitgevocr kan word (dic $B \wedge M$ en $\triangle A S M$ simuleer dic skcidingsvlak tussen land $\mathrm{en}$ oseaan met verskillende roosterresolusies).

'n Voorvereiste vir die suksesvolle simulasic van streeksklimate deur die GKM-tegniek is uiteraard dat die aandrywende sinoptieseskaal-AASM-simulasies realisties moet wees. Indien die eienskappe van hierdie klimaat, soos die migrasie van antisiklone en afsnylae oor suidelike Afrika of die posisic van die intertropiese (interoseaan) konvergensicsone onrealisties voorkom, is dit hoogs onwaarskynlik dat die $B \wedge M$ foute sal korrigeer. Dit is dus nodig om die sinoptieseskaal-klimatologic van die AASM deeglik te toets. ${ }^{5.7}$ ' $n$ Belangrike verskynsel wat uit GKM-eksperimente na vore tree, ${ }^{5}$ is dat die gemiddelde sinopticseskaal-klimatologic van 'n BAM normaalweg goed vergelyk met dié van die aandrywende AASM. Dit is 'n aanduiding dat, ten minste met die eenrigting-benadering, 'n BAM nie foute in die laeroosterresolusie aandrywende sirkulasiepatrone sal korrigeer nic. Hierdie resultaat beklemtoon die belangrikheid van bevredigende AASM-velde.

\section{GKM-EKSPERIMENTE OOR SUIDELIKE AFRIKA}

Die enigste twee genestelde klimaatsimulasic-cksperimente wat tot op hede oor suidelike A frika uitgevoer is, ${ }^{21,22}$ is gedoen deur die gebruik van DARLAM (Division of Atmospheric Research Limited Area Model) van die CSIRO (Commomwcalth Scientific and Industrial Research Organisation) in Australië. Hierdic model is ontwikkel vir sowel mesoskaalstudies as klimaatsveranderingseksperimente. ${ }^{20}$ Die model is 'n twee-tydvlak, semiimplisiete, hidrostatiese, primitiewe vergelykingsmodel. Dit gebruik 'n Arakawa afwisselende C-roosterveld en semi-Lagrange horisontale adveksie met bikubiese ruimtelike interpolasie. Gedurende die eksperimente is die model genestel binne 'n vroeëre weergawe van die CSIRO9 MARK II (R21) AASM.?

In die eerste eksperiment ${ }^{21}$ is daar gepoog om dic huidige Januarie-klimaat oor suidelike A frika te simuleer. Dic eksperiment het bestaan uit twintig Januarie-simulasies genestel teen 'n roosterresolusie van $125 \mathrm{~km}$ binne die CSIRO9 MARK II (R21) AASM. Die gevolgtrekking is gemaak dat DARLAM 'n meer akkurate simulasie van die klimaat oor suidelike Afrika verskaf as die AASM. Oor die steil platorand van oostelike SuidAfrika simuleer DARLAM egter meer reënval as die AASM, waarvan die simulasies alreeds die waargenome reënval oorskry. ${ }^{6,7}$

In die tweede eksperiment ${ }^{22}$ is DARL $A M$ gebruik om die volle seisonale klimaatsiklus van suidelike Afrika in 'n 10 jaarsimulasic te simuleer. Weereens is daar gevind dat DARLAM die reënval oor dic oostelike dele van Suid-Afrika oorskat. Ten spyte van hierdie probleem het DARLAM, relatief tot dic $\Lambda \Lambda \mathrm{SM}$, 'n merkbare verbetering in die simulasic van die mesoskaalklimaat verskaf. Daar word vermoed dat DARLAM sc semi-implisicte, semi-Lagrange-integrasieskema vertikale snelhede in die teenwoordigheid van skerp orografiese gradiënte oorskat. Dit kan moontlik die oorskatting van reënval oor die suidoostelike platorand verklaar, en dui daarop dat verbetering in dic simulasic van strecksreënvaltotale alleen moontlik sal wees indien dic BAM verder verbeter sou word. ${ }^{22}$

\section{GEVOLGTREKKINGS EN VOORSTELLE}

Vorige resultate van DARLAM oor sowel suidelike Afrika en $\Lambda$ ustralasië is bemoedigend, en dui daarop dat DARLAM die potensiaal het om betekenisvolle verbeterings aan te bring aan die simulasie van mesoskaal klimatologiese besonderhede. Omdat dic GKM-tegnick fisies, en nic empiries gebaseer is nic, kan 'n soortgelyke verbetering verwag word wanneer klimatologiese toestande wat verskil van die teenswoordige gesimuleer word.

Alhocwel dic GKM-tegnick groot belofte inhou vir hoëroosterresolusie-klimaatsimulasies oor suidelike $\Lambda$ frika, is dit steeds in ' $n$ ontwikkelingsfase. Huidige BAM'e het bekende tekortkominge in fisiese parameteriserings (konveksie en fisiese prosesse aan die oppervlak) en numeriese algoritmes (byvoorbeeld die berekening van die drukgradiëntkrag in hidrostatiese modelle). Hierdic tekortkominge affekteer $B \wedge M-k$ limaatsimulasies, en daarom is dit noodsaaklik om die mees geskikte fisiese parameteriscrings te kies en die modelkonfigurasic vir 'n gegewe studic te verificer. So is dit byvoorbeeld nodig om deur middel van sensitiwiteitscksperimente vas te stel watter parameteriseringskema vir konveksie die mees geskikste sal wees vir suidelike Afrika.

In vorige klimaatsimulasies oor suidelike Afrika met DARLAM het dit geblyk noodsaaklik te wees om Madagaskar binne die BAM-gebied in te sluit, terwyl die beperkte gebied se rande so ver as moontlik van dic kuslyne moes wees. Eksperimente wat oor Australië uitgevoer is, het aangetoon dat dit moontlik sal wees om gebiede binne die trope in die beperkte gebied in te sluit sonder dat die "stasionêre probleem" die simulasie wesenlik sou besoedel.

Huidige planne vir dic DARLAM genestelde modelleringsraamwerk oor suidelike Afrika behels intensicwe modelverifikasie deur gebruik te mak van teenswoordigetyd- klimatologiese data. Daar word beoog om die model te loop met 'n horisontale roosterresolusie van ongeveer $40 \mathrm{~km}$. Die outeurs beplan voorts om deur middel van numeriese eksperimente vas te stel of DARL $A M$ se oorskatting van reënval oor dic oostelike helfte van Suid-Afrika toegeskryf kan word aan dic numeriese skema wat in die model gebruik word vir vogadveksic. Mediumtermyn-doclwitte is om DARLAM te gebruik as deel van 'n hoëroosterresolusie seisoenale reënvoorspellingskema, asook om kweekhuisgas-geinduseerde klimaatsverandering scenario's oor suidelike Afrikante verkry.

\section{SUMMARY}

Future changes in global climate may cause dramatic changes in the climate of southern Africa. Shifting climate zones and more frequent storms, droughts, floods and heatwaves may lead to social, economical and political disruptions. ${ }^{4}$ Modelling future climate on a regional scale is therefore an issue of funda- 
mental importance.

Atmospheric general circulation models ( $A G C M s$ ) have become the primary method for simulating climate. ${ }^{5} \wedge$ GCMs capture the main characteristics of and interannual variation in the general circulation over southern $\Lambda$ frica satisfactorily. $6,7,8$ However, their simulations of climate on a regional scale are meagre. The main reason for this result is the low horizontal grid resolution of AGCMs. " " Computational requirements prevent AGCMs to be run at mesoscale grid-resolutions of a few kilometres to about $100 \mathrm{~km}{ }^{5.9}$ The impact of local forcings such as complex orography, and important small-scale circulations such as tropical cyclones and land-sea breezes cannot be resolved properly at typical $\triangle$ GCM grid resolutions". However, mesoscale forcings and circulations have an important modifying influence on the southern $\Lambda$ frican climate. For example, the complex orography of the Klein Karoo area, Lake Victoria's, and land-sea breczes $11,12,13,14$ all contribute to local-scale modifications of the southern $\Lambda$ frican climate (Figures 1 and 2 ). The climate of the north-eastern escarpment areas of South $\Lambda$ frica is significantly influenced by interactions between mesoscale and synoptic-scale circulations (Figure 3 ).

The technique of nested climate modelling (NCM) can be used to obtain detailed climate simulations over limited areas of the earth. NCM involves the nesting of a high grid-resolution limited area model ( $L A M)$ within the $\Lambda$ GCM over the area of interest. The $\triangle \mathrm{GCM}$ supplies the $\mathrm{L} \wedge \mathrm{M}$ with initial and boundary conditions. With a grid resolution of $10-100 \mathrm{~km}$, the limited area model is able to simulate some of the mesoscale propertics of the circulation. The one-way nesting procedure is depicted in Figure 4.

The LAM domain should be large enough for mesoscale circulations to develop fully within it, ${ }^{17,18}$ yet small enough to prevent the LAM simulation from diverging from the AGCM simulation on the synoptic-scalc. ${ }^{17,18}$ The LAM grid resolution should be fine enough for the mesoscale circulations to be captured. $A$ compromise has to be reached regarding the grid resolution required and available computer power.

It is necessary to include Madagascar in a LAM domain over southern Africa, since the topographical fields of typical AGCMs do not resolve the island properly. ${ }^{21}$ It is also advisable to place the boundaries of the limited area far away from the coastlines of the subcontinent.

Previous NCM experiments over southern Africa utilised the Division of Atmospheric Research Limited Area Model (DARLAM), nested within the CSIRO9 MARK II (R21) AGCM. Compared to the AGCM, DARLAM provided a more accurate and detailed simulation of southern $A$ frican climatc. ${ }^{21}$ However, the rainfall simulated by DARLAM over the eastern parts of South Africa is too high. ${ }^{21}$ It is speculated that this overestimation results from the overestimation of vertical velocities in regions of steep orography. ${ }^{22}$

It was concluded that the technique of NCM has enormous potential for improving the simulation of present and future climate over South Africa. However, the technique is still in its developing stage. Experiments have to be conducted to determine which numerical and parameterisation schemes are the most suitable for southern African conditions. The authors intend to use DARLAM to obtain scenarios of future climatic patterns over southern Africa.

\section{BEDANKINGS}

Dic outeurs bedank graag dic Waternavorsingskommissic wat die navorsing met DARLAM finansieel ondersteun. In die besonder word dr. Green bedank vir sy volgehoue belangstelling en aanmoediging.

\section{LITERATUURVERWYSINGS}

1. Delworth, T.L., Malliman, J.D., Kuutson, T.R. (1999). Changes in heat index associated with $\mathrm{CO}_{2}$ - induced global warming, Climate Change, 43, 369-386.

2. Bazzaz, I:A. (1998). Tropical forests in a future climatc: Changes in biological diversity and impact on the global carbon cycle, $\mathrm{Cli}$ male Change, 39, $317-336$.

3. Nobre, C.A., Scliers, P.J., Sluukla, J. (1991). Amazonian Deforestation and Regional Climate, $J$. Climate, 4, 957-988.

4. Rowlands I.H. (1998). Climate change cooperation in Southern Africa (Earthscan Publications Limited, London, UK).

5. Giorgi, I:., Mcarns, L.O. (1991). Approaches to the simulation of regional climate clsange: A revicw, Rev. Geophys., 29, 191-216.

6. Joubcrt, A.M. (1997). Simulations by the atmosplicric intercomparison project of atmospheric circulation over southern Africa, Int. J. Climatol. 17, 1129-1154.

7. Rautenbach, C.J. de W., Engelbrecht, I.A. (2000). Klimaatevaluasic van dic CSIRO-9 Mcrk II (R2I) globalc atmosfericse algemenesirkulasic-model. Ingedien by Die Suid-Afrikaanse Tydskrif vir Natummetensk(a) en Tegnologie.

8. lingelbreclit, I:A., Rautenbach, C.J. de W. (2000). The conribution of extra-tropical sca-surface temperature anomalics to the 1996/97 model simulated rainfal! and mean sca-level pressure over South Africa and adjacent occans. Ingedien by Water $S A$.

9. McGrcgor, J.L., Walsh, K.J., Katzfey, J.J. (1993). Nested Modelling for regional Climate Studies. Modelling Change in Environmental Systems (John Wilcy and Sons Lid.) Chapter 15 pp. $376-$ 386.

10. Joubert, A.M., Mason, S.J., Galpin, J.S. (1996). Droughts over southcrn Africa in a doubled-CO, climate, Imt. J. Climatol., 16, 1149 1156 .

11. Jackson, S.P. (1954). Sca breczes in South Africa, S.A. Geogr. Jour, 36, 13-23.

12. Preston-Whytc, R.A. (1969). Sca brecze studics in Natal, S.A. Geogr. Jour., 51, 38-48.

13. Tyson, P.D., (1966) Examples of local air circulations over Cato Ridge during July 1965, S.A. Geogr. Jour., 48, 13.

14. Tyson, P.D., (1968) Southeastcrly winds over Natal, J. for Geogr., $111,237-246$.

15. Asnani, G.C. (1993). Tropical Meteorology (Punc, India).

16. Garstang, M, Kclbc, B.E., Emmitt, G.D., London, W.B. (1987). Generation of Convective Storms over the escarpment of Northcastem South Africa, Mon. Wea. Rev., 115, 429-443.

17. Joncs, R.G., Murphy, J.M., Noguer, M. (1995). Simulation of climate change over Europe using a nested regional climate model. 1: Assessment of control climatc, including sensitivity to location of latcral boundarics, Quart. J. Roy. Meteor. Soc., 121, 1413-1449.

18. Podzun, R., Cress, A., Majcwski, D., Renner, V. (1995). Simulation of European Climate with a limited arca model. Part II. AGCM boundary conditions, Contrib. Atmos. Phys. 68, 205-225.

19. Errico, R., Baumlsefner, D. (1987). Predictability experiments using a high resolution limited-arca model, Mon. Wea.Rev., 115, 408418 .

20. Walsh, K., McGregor, J.L. (1995). January and July Climatc simulations over the Australian region using a limited area model. J. Climate, 8, 2387-2403.

21. Joubert, A.M., Katzfcy, J.J., McGregor, J.L., Nguyen, K.C. (2000). Simulating mid-summer climate over Southern Africa using a nested regional climate model, Ingedien by $J$. Geophys. Res.

22. Joubert, A.M., Katzfcy, J.J., McGregor, J.L. (2000). Daily rainfall simulations over South A frica using a nested regional climate model. Ingedicn by $S . A f r . J$. Sci. 